The following pages constitute the final, accepted and revised manuscript of the article.

Naoko Yanagisawa, Linda Geironson, Waleed Abu Al-Soud, Åsa Ljungh

"Expression of matrix metalloprotease-2, -7, and -9 on human colon, liver and bile duct cell lines by enteric and gastric Helicobacter species."

FEMS Immunol Med Microbiol. 2005 May 1;44(2):197-204.

Publisher: Elsevier.

Use of alternative location to go to the published version of the article requires journal subscription.

Alternative location: http://dx.doi.org/10.1016/j.femsim.2004.11.009 


\title{
Expression of matrix metalloprotease-2, -7 , and -9 on human colon, liver and bile duct cell lines by enteric and gastric Helicobacter species
}

\author{
Naoko Yanagisawa, Linda Geironson, Waleed Abu Al-Soud, Åsa Ljungh* \\ Medical Microbiology, Dermatology and Infection, Lund University, Sölvegatan 23, \\ SE223 62 Lund, Sweden
}

*Corresponding author: Associate professor Åsa Ljungh,

Medical Microbiology, Dermatology and Infection, Lund University, Sölvegatan 23, SE 22362 Lund, Sweden

Telephone: +46-46-173283

Telefax: $+46-46-152564$ 


\section{Abstract}

Gastric and enteric Helicobacter species have been associated with malignant and inflammatory diseases of the stomach, liver, gall bladder and intestine. Matrix metalloproteinases (MMPs) participate in degradation of extracellular matrix (ECM), which allows bacteria to come in contact with and interact with the cells. Enhanced level of MMPs facilitates metastasis and cell invasion of tumor cells by removal of physical barriers, as well as modulation of cell adhesion and biologic activities of proteins residing in the ECM. The aim of this study was to evaluate the effect of gastric and enteric Helicobacter on induction of MMPs in hepatocytes and epithelial cells of gall bladder and colon. Human hepatocytes HepG2, gall bladder epithelial cells TFK-1, and colon epithelial cells HT29 were infected with strains of $H$. pylori cagA+, cagE+, H. pylori cagA-, cagE-, H. pullorum, H. cholecystus, $H$. bilis and $H$. hepaticus. Protein levels of MMPs were analyzed by enzyme-linked immunosorbent assay and immunohistochemistry. Reverse transcription-quantitative polymerase chain reaction was used to study mRNA levels. Increased expression of MMP-2 and MMP-9 was observed on HepG2, TFK-1 and HT29 infected with H. pylori cagA+, cagE+ and $H$. cholecystus strains. $H$. pylori cagA+, cagE+, H. cholecystus, $H$. pullorum, $H$. bilis and H. hepaticus strains increased expression of MMP-7 on HT29, compared to uninfected control cells. The effect of MMP upregulation on HepG2, TFK-1 and HT29 was bacterial dose dependent. H. pylori cagA-, cagE- strain did not increase expression of MMPs. Inducible MMPs on colon and bile duct epithelial cells as well as hepatocytes cells may play an important role in facilitating invasion and progression of cancer by Helicobacter species colonizing the hepatobiliary and gastrointestinal tract.

Keywords: Enteric Helicobacter, matrix metalloproteinase, epithelial cells, bile duct, colon, liver 


\section{Introduction}

The Helicobacter genus are gram-negative bacteria, and includes more than 20 adequately characterized species to date [1]. These species have been isolated from a number of hosts, such as humans and other primates, pigs, cats, dogs, poultry, and rodents. Moreover, within their hosts, Helicobacter species have been identified from both the gastric and the enterohepatic niches of the gastrointestinal tract. H. pullorum, first detected in the liver and intestinal contents of poultry [2], has since been isolated from humans with gastroenteritis [3]. $H$. bilis and $H$. hepaticus have been isolated from the liver and the intestinal mucosa from mice, and has been implicated to be associated with rodent chronic hepatitis and liver cancer $[4,5] . H$. cholecystus has been identified from the gall bladder of hamsters [6]. H. pylori is the most widely studied species and is associated with human gastric pathology [7].

The matrix metalloproteinases (MMPs) comprise a family of over 25 members which are secreted from a variety of cells, and are normally found as pro-enzymes in the extracellular matrix (ECM). When these molecules are activated, they participate in degradation of ECM proteins [8], and allows bacteria to come into contact with and interact with the cells. An enhanced level of MMPs also facilitates metastasis and cell invasion of tumour cells by removal of physical barriers, as well as modulation of cell adhesion and biologic activities of proteins residing in the ECM [9]. MMP-9 (gelatinase B) digests denatured collagens, such as the major component of the basement membrane type IV collagen, and has three repeats of a type II fibronectin domain in the catalytic site, which bind to the substrates including collagens, gelatine and laminin [8]. MMP-2 (gelatinase A) is structurally related to MMP-9 and cleaves ECM proteins such as collagen type I and IV [8]. MMP-7 (matrilysin) is the smallest of all the MMPs consisting of a pro-peptide domain and a catalytic domain [8]. It degrades various matrix substrates, including proteoglycans, elastine, and gelatine, and cleaves non-matrix proteins from the cell surface, including E-cadherin, pro-tumour necrosis 
factor $\alpha$ and Fas ligand [8]. MMPs can be activated by proteinases, or in vitro, by chemical agents, low $\mathrm{pH}$ and heat treatment [8].

In two gastric epithelial cell lines, MKN45 and MKN28, MMP-9 expression has been shown to be upregulated by $H$. pylori possessing the cytotoxin-associated gene pathogenicity island (cag PAI), though independent of the vacuolating cytotoxin vacA locus [10]. The cag PAI has also been implicated to associate with upregulation of MMP-7 in colon epithelial cell line HT29 stimulated by $H$. pylori [11]. However, whether the non-gastric enteric species of the Helicobacter genus is associated with MMP stimulation has not been investigated, though the bacteria have been linked to inflammatory and ulcerative diseases as well as cancer of the enterohepatic tissue [1]. The object of this study was to elucidate the effect on MMP-2, MMP-7 and MMP-9 by enteric and gastric Helicobacter species at protein expression as well as gene expression levels. 


\section{Materials and methods}

\section{1. Bacterial strains and culture conditions}

Five Helicobacter strains were obtained from Culture Collection University of Göteborg (CCUG), including four enteric Helicobacter strains: $H$. pullorum CCUG 33838, H. cholecystus CCUG 38167, H. bilis CCUG 38995 and H. hepaticus CCUG 33837. H. pylori CCUG $17874 \mathrm{cagA}+, \mathrm{cagE}+$, vacA s1m1, and a chronic gastritis isolate H. pylori 15/96 cagA, cagE-, vacA s2m2, were typed by PCR. Bacteria were grown on Blood-Brucella agar with $0.1 \%$ activated charcoal in microaerophilic milieu, generated with Anoxomat ${ }^{\circledR}$ (MART Microbiology BV, Licthenvoorde, Netherlands) in vented GasPak jars at $37^{\circ} \mathrm{C}$. Bacteria were sub-cultured every second day. For infection experiments, bacteria were harvested from agar plates, re-suspended in warm cell culture media, and were immediately incubated with the cell lines. Gram stain of bacteria was accomplished before sub-cultivation and inoculation with the cells to exclude contamination and to detect the rate of bacterial spiral and coccoid forms.

\section{2. Cell lines and culture conditions}

Human cell line cultures were maintained on $75 \mathrm{~cm}^{2}$ cell culture flasks (TPP AG, Trasadihen, Switzerland). Liver cell line HepG2 and biliary tract epithelial cell line TFK-1 were cultured in RPMI 1640 (ICN, Inc., OH) supplemented with $10 \%$ fetal bovine serum (FBS, Invitrogen, Lidingö, Sweden) and 2 mM L-glutamine (ICN, Inc., OH). Colon epithelial cell line HT29 was grown in McCoy media (Invitrogen, Lidingö, Sweden) with $10 \%$ FBS and 2 mM Lglutamine (ICN, Inc., OH). Cells were incubated at $37^{\circ} \mathrm{C}$ with $5 \% \mathrm{CO}_{2}$ and were split once a week. Twenty-four hours prior to infection, cells were transferred to 96 -well tissue culture plates (TTP AG, Trasadihen, Switzerland), $100 \mu 1$ per well, or to chamber glass slides (Nunc Lab-Tek $^{\mathrm{TM}}$, Roskilde, Denmark), $2 \mathrm{ml}$ per slide. 


\section{3. Enzyme-linked immunosorbent assay (ELISA)}

Bacterial doses of $10^{5}, 10^{6}$, and $10^{7}$ colony forming units (CFU) were inoculated to $2 \times 10^{4}$ cells in order to evaluate the dose dependency of bacterial stimulation for MMP expression. Infected cells on 96 -well plates were cultured for 3,24 or 48 hours at $37^{\circ} \mathrm{C}$ to evaluate the time course of MMP induction by bacteria. The wells were washed twice with $0.02 \mathrm{M}$ phosphate buffered saline pH 7.2 containing $0.15 \mathrm{M} \mathrm{NaCl}$ (PBS), and fixed with $100 \%$ methanol at $-20^{\circ} \mathrm{C}$ for 10 minutes. Endogenous peroxidase activity was blocked with $0.75 \%$ $\mathrm{H}_{2} \mathrm{O}_{2}$ and $0.1 \% \mathrm{NaN}_{3}$ in PBS at $37^{\circ} \mathrm{C}$ for 20 minutes. Cells were then washed, and primary monoclonal antibodies diluted in $1 \%$ bovine serum albumin in PBS were added (MMP-2 and MMP-9, final concentrations $0.2 \mu \mathrm{g} / \mathrm{ml}$, Santa Cruz Biotechnology, Inc., CA; MMP-7 final concentration $0.3 \mu \mathrm{g} / \mathrm{ml}$, Oncogene Research Products, Cambridge, MA). The plates were incubated for 1 hour and 30 minutes at $37^{\circ} \mathrm{C}$ and then washed. Secondary HRP-conjugated antibody (final concentration $0.6 \mu \mathrm{g} / \mathrm{ml}$ ) was incubated for 1 hour and 15 minutes at $37^{\circ} \mathrm{C}$ and then washed. Substrate for peroxidase o-phenylenediamine (Sigma-Aldrich, St. Louis, MO) was incubated for approximately 15 minutes in dark, and the reaction was stopped by addition of $1 \mathrm{M} \mathrm{H}_{2} \mathrm{SO}_{4}$. The absorbance was measured on a spectrophotometer (Labsystem Multiscan PLUS, Labsystem OY, Helsinki, Finland) at $492 \mathrm{~nm}$.

\section{4. Immunohistochemistry}

Helicobacter strains $2 \times 10^{7}$ CFU was inoculated to $4 \times 10^{5}$ cells of HT29, HepG2 or TFK-1. After 24 hours of co-cultivation, the chamber slides were washed and the cells were fixed with acetone at $-20^{\circ} \mathrm{C}$ for 10 minutes. Slides were then washed in PBS and endogenous peroxidase activity was blocked by addition of PBS supplemented with $0.03 \% \mathrm{H}_{2} \mathrm{O}_{2}$ and 0.1 $\% \mathrm{NaN}_{3}$. After washing, primary monoclonal antibodies against MMP-7 (final concentration $3 \mu \mathrm{g} / \mathrm{ml}$, Oncogene Research Products, Cambridge, MA), MMP-2 or MMP-9 (final 
concentrations $2 \mu \mathrm{g} / \mathrm{ml}$, Santa Cruz Biotechnology, Inc., CA) were added and incubated for 2 hours at room temperature. Normal mouse serum (final concentration $20 \mu \mathrm{g} / \mathrm{ml}$, DakoCytomation, Älvsjö, Sweden) was used as isotype control. Cells were washed and incubated with horse radish peroxidase (HRP)-conjugated secondary anti-mouse antibody (final concentration $20 \mu \mathrm{g} / \mathrm{ml}$, DakoCytomation, Älvsjö, Sweden) for 30 minutes at room temperature. The substrate for peroxidase $0.05 \% 3,3$ '-diaminobenzidine-tetrahydrochloride (Sigma-Aldrich, St. Louis, MO) in PBS was added for 2 minutes and the reaction was stopped with $\mathrm{H}_{2} \mathrm{O}$. Counter staining of the nuclei was performed by hematoxylin for 8-10 seconds, stopped with $\mathrm{H}_{2} \mathrm{O}$. The slides were dehydrated in $70 \%$ ethanol, $95 \%$ ethanol, $99.5 \%$ ethanol and finally in xylene, and mounted with DePeX (Sigma-Aldrich, St. Louis, MO). The slides were examined on an inverted microscope (Olympus CK40, Tokyo, Japan).

2. 5. RNA isolation, primer design, and reverse transcription-quantitative polymerase chain reaction $(R T-Q P C R)$

Total RNA was extracted from $2 \times 10^{6}$ cells of HT29, HepG2 and TFK-1, infected with Helicobacter strains $1 \times 10^{8} \mathrm{CFU}$, or uninfected, by using RNeasy Mini kit with QIA shredders (Qiagene GmbH, Hilden, Germany). Quantity and purity of RNA were measured by $A_{260} / A_{280}$ adsorption using U-110 spectrophotometer (Hitachi, Tokyo, Japan). The different primer pairs used in this study were constructed using Vector NTI $^{\circledR}$ Suite version 8.0 (InforMax, Frederick, Maryland, USA). All primers used in this study were purchased from MWG-Biotech AG, Ebersberg, Germany; MMP-7 forward: 5'TTTGATGGGCCAGGAAACAC-3', MMP-7 reverse: 5'-GGGGATCTCCATTTCCATAG3', MMP-9 forward: 5'-GAAGATGCTGCTGTTCAGCG-3', MMP-9 reverse: 5'ACTTGGTCCACCTGGTTCAA-3', glyceraldehydes-3-phosphate dehydrogenase (GAPDH) forward: 5'- CTCATTTCCTGGTATGACAACGAA-3', GAPDH reverse 5'- 
AAGGGGTCTACATGG CAACT-3'. To reduce the effect of DNA contamination in the extracted RNA, the forward primers were designed to cross intron/exon boundaries to ensure that the products detected resulted from amplification of cDNA rather than genomic DNA. The primer specificity was determined by using BLASTN 2.2.1 (http://www.ncbi.nlm.nih.gov/BLAST/) [12]. For RT-QPCR, total RNA (0.5 $\mu \mathrm{g})$ was reverse transcribed in $20 \mu \mathrm{l}$ reaction mixture containing $1 \times$ reaction buffer, $0.5 \mathrm{mM}$ deoxynucleoside triphosphates (dNTPs), $10 \mathrm{mM}$ dithiothreitol, RNase inhibitor 40 units (Invitrogen, Lidingö, Sweden), oligo(dT) primer $2 \mu \mathrm{g}$ (Amersham Plc., Little Chalfont, Buckinghamshire, UK), and Superscript II reverse transcriptase 200 units (Invitrogen, Lidingö, Sweden) at $42^{\circ} \mathrm{C}$ for 50 minutes. The cDNA $(2 \mu 1)$ was amplified in a $25 \mu 1$ reaction mixture containing $0.2 \mathrm{mM}$ of each dNTPs, $0.5 \mu \mathrm{M}$ of forward and reverse primers, 1/100,000 Sybr Green I (Roche Diagnostics Scandinavia, Bromma, Sweden), 1 U AmpliTaq DNA polymerase and $1 \times$ PCR buffer (Applied Biosystems, Foster City, CA, USA). Amplification and detection of amplified PCR products was done by using the Rotorgene (Corbett Research, Sydney, Australia). Amplification conditions were predenaturation at $95^{\circ} \mathrm{C}$ for 10 minutes, followed by 40 cycles of denaturation at $95^{\circ} \mathrm{C}$ for 20 seconds, annealing at $57^{\circ} \mathrm{C}$ (MMP-7) or $53^{\circ} \mathrm{C}$ (MMP-9 and GAPDH) for 20 seconds, and extension at $72^{\circ} \mathrm{C}$ for 20 seconds. The specificity of the amplification was determined by melting curve analysis and gel electrophoresis analysis of the amplified PCR product. Melting curve analysis of the amplified PCR products was done immediately after PCR, by increasing the temperature linearly from 60 to $95^{\circ} \mathrm{C}$ at a rate of $1^{\circ} \mathrm{C}$ per second with the signal acquisition mode set to continuous. The threshold cycle $\left(\mathrm{C}_{\mathrm{T}}\right)$, which is the intersection between each fluorescence curve and the crossing line, was calculated using the Rotorgene software. Simultaneously, $10 \mu$ l of PCR products were analysed by electrophoresis in a $1.5 \%$ agarose gel containing ethidium bromide (final concentration $0.5 \mu \mathrm{g} / \mathrm{ml}$ ). PCR product size was estimated by Marker Plus (Fermentas GmbH, 
St. Leon-Rot, Germany), which was run in parallel. The expression of target genes was normalized against GAPDH gene in a corresponding sample. MMP-7 gene expression in Helicobacter-infected cells was presented as fold induction compared to the uninfected control cells: Fold induction MMP-7 $=\left(\mathrm{GAPDH} \mathrm{C}_{\mathrm{T} \text { infected }} / \mathrm{MMP}-7 \mathrm{C}_{\mathrm{T}}\right.$ infected $) /\left(\mathrm{GAPDH} \mathrm{C}_{\mathrm{T}}\right.$ uninfected / MMP-7 $\mathrm{C}_{\mathrm{T}}$ uninfected). Equivalent formula was utilized to calculate fold-induction of MMP-9 genes.

\section{6. Statistics}

Mann-Whitney $U$ test was performed to analyze the significance of MMP induction in human cell lines infected by Helicobacter strains compared to uninfected control cells. A $p$ value of $<0.05$ was considered as significant difference. 


\section{Results}

3.1. Optimization of conditions for induction of MMP-2, MMP-7 and MMP-9 expression on HT29, HepG2 and TFK-1

MMP-2, MMP-9 and MMP-7 on HT29, HepG2 and TFK-1 was measured by ELISA subsequent to 3, 6 and 24 hours of infection with $H$. pylori 17874, which showed an increase of expression by time reaching maximum levels at 24 hours (data not shown). In a separate experiment, $10^{5}, 10^{6}$ and $10^{7} \mathrm{CFU}$ of $H$. pylori 17874 were infected with $2 \times 10^{4}$ cells for 24 hours, which resulted in significant upregulation of MMP expression compared to uninfected control cells when more than $10^{6} \mathrm{CFU}$ was added, and the MMP expression levels increased in a bacterial dose dependent manner (data not shown). Therefore, each of the six Helicobacter strains was inoculated with cells at a ratio of $\underline{50: 1}$ for 24 hours to analyze MMP induction on enterohepatic cell lines by ELISA, immunohistochemistry and RT-QPCR.

\subsection{ELISA of MMP-2, MMP-7 and MMP-9 on HT29, HepG2 and TFK-1}

ELISA revealed significant increase of MMP-2 and MMP-9 expression on HT29, HepG2 and TFK-1 infected by $H$. pylori 17874 and $\underline{H}$. cholecystus, compared to uninfected control cells, while the other enteric Helicobacter had only minor effects on upregulation of MMPs on these cell lines (Fig1, 2). When expression of MMP-7 was analyzed on HT29, H. pylori 17874, H. pullorum, H. cholecystus, H. bilis and $\boldsymbol{H}$. hepaticus significantly increased expression, whereas the effect of $H$. pylori 15/96 on expression of MMP-7 was not significant (Fig 3). 
3.3. Immunohistochemistry of MMP-2, MMP-7 and MMP-9 on HT29, HepG2 and TFK-1

HT29, HepG2 and TFK-1 infected with H. pylori 17874 and $\underline{H}$. cholecystus showed specific positive reaction with antibodies against MMP-2 and MMP-9, whereas uninfected control cells did not (data not shown). HT29, HepG2 and TFK-1 infected with $\underline{\text { H. pullorum, }}$ H. pylori 17874, $\underline{H}$. cholecystus, $\boldsymbol{H}$. bilis and $\boldsymbol{H}$. hepaticus showed specific positive reaction for MMP7, but not those infected with $H$. pylori 15/96 or the uninfected control (Fig 4 and data not shown).

\subsection{RT-QPCR of 2 -2, MMP-7 and MMP-9 in HT29, HepG2 and TFK-1}

RT-QPCR analysis revealed higher levels of MMP-7 mRNA in HT29 by $\underline{3 \text { hours of }}$

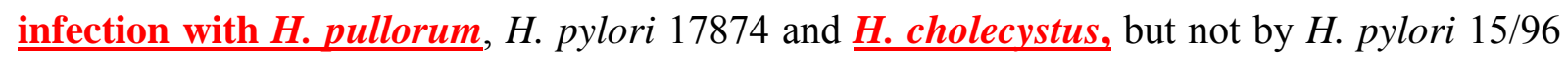
or those uninfected (Fig 5). MMP-7 mRNA in HT29 induced by H. pullorum, H. pylori 17874 and $\underline{\text { H. cholecystus, }}$ remained at higher levels than those uninfected at 6 and 24 hours of infection (data not shown). TFK-1, HepG2 and HT29 infected with H. pylori 17874 and $\underline{\text { H. cholecystus demonstrated higher levels of MMP-9 mRNA at 3, } 6 \text { and } 24 \text { hours of }}$ infection, whereas those infected with $H$. pylori 15/96 or uninfected did not (data not shown), consistent with the results of ELISA and immunohistochemistry. 


\section{Discussion}

The present study shows that the oncogenic pathogen $H$. pylori infection causes upregulation of MMP-2, MMP-7 and MMP-9 in human enterohepatic cells, and that it is dependent on intact cag PAI. Moreover, we have demonstrated that enteric species of the Helicobacter genus are also capable in upregulation of MMP-2, MMP-7 and MMP-9 in colon and bile duct epithelial cells and hepatocytes. In contrast to other inflammatory mediators such as the chemokine IL-8, which has been shown to be upregulated within few hours after $H$. pylori infection [13], expression of MMP-2, MMP-7 and MMP-9 by Helicobacter species was prolonged to a later phase of infection, which-may indieate-atent role-of MMPs in Helieobaten infection in progression-to-advaneed-stages-of diseases-of the-gastroenterie and hepatobiliany tacts. MMP-2, MMP-7 and MMP-9 are important metalloproteinase enzymes which are upregulated in enterohepatic cancers and have been considered to be important markers in human cancer progression. Links between MMP-9 in bile with liver metastasis in colorectal cancer [14] and MMP-2 in advanced cholangiocarcinoma in contrast to normal or non-metastatic livers [15] have been reported. In animal models, Min (multiple intestinal neoplasia) mice developed adenomas in the small intestine and colon, whereas MMP-7-deficient Min mice resulted in fewer tumors [16]. MMPs promote tissue invasion and metastasis in various cancers through degradation of ECM. The type IV collagenases MMP-2 and MMP-9 have been found to play a key role in the invasive ability of tumors, as basement membrane is composed primarily of type IV collagen [8]. In addition, substrates of MMP-7 include pro-apoptotic Fas ligand. Thus, decreasing the ability to suppress apoptosis may predispose to proliferation and tumorgenesis [17].

In the present study, expression of Helicobacter-induced MMPs was bacterial dose dependent, indicating that stimulation of enterohepatic cells in induction of MMPs may 
require a specific ligand-receptor interaction. Exposure of mouse or human mucosal epithelial cells to other gram-negative bacteria, such as Escherichia coli and Pseudomonas aeruginosa, induced a strong and sustained induction of MMP-7 by the monomeric component of flagella, flagellin, but not by lipopolysaccharide [18]. The cag PAI of H. pylori encodes components of the type IV secretion system by which the bacteria attach to the cells and delivers the CagA protein into the cytoplasm [13]. Crawford et al. has reported in gastric epithelial cell line AGS that $H$. pylori possessing the cag PAI, but not the cag mutants, induced expression of MMP-7 through intracellular signal pathway involving extracellular signal regulated kinase 1/2 activation [19]. Also in AGS, Wroblewski et al. reported that MMP-7 induction by cag positive $H$. pylori involved Rac activation through nuclear factor kappa B (NF-kB), and Rho activation through NF- $\mathrm{B}$ and activator protein 1 [20]. The involvement of cag PAI seems crucial in MMP expression, since in our study, the H. pylori cagA+, cagE+ strain induced expression of MMP-2, MMP-7 and MMP-9 in bile duct and colon epithelial cells, as well as hepatocytes, whereas the H. pylori cagA-, cagE- strain did not. However, cag PAI may not be the only pathogenic factor to induce MMPs, since the enteric Helicobacter, which lack cag PAI, were demonstrated in the present study to induce significant levels of MMP-7 on colon epithelial cells. Moreover, H. cholecystus stimulated MMP-2 and MMP-9 expression on colon and biliary tract epithelial cells as well as hepatocytes, as did cag positive $H$. pylori. Although all the enteric bacteria investigated in the present study are members of the genus Helicobacter, they are different species associated with enterohepatic diseases in various hosts, most of which have not been studied in the same depth to date as $H$. pylori regarding virulence factors. In other enteric bacteria that share the enteric niches for colonization, cytolethal distending toxin (CDT) has been demonstrated to play an important role in pathogenicity, as has been demonstrated in several enteric Helicobacter strains [21]. All four strains of enteric Helicobacter used in the present study possess $c d t B$, which encodes 
the functional domain of CDT, confirmed by PCR by using primers generated from species specific $c d t B$ sequence (Abu Al-Soud, unpublished data). However, heterogenic expression of MMPs induced by the enteric Helicobacter strains, may suggest an involvement of pathogenic factors other than CDT. Further investigation on the pathogenic factors of enteric Helicobacter responsible for MMP induction is needed.

Considerable evidence to support the role for MMPs in progression of inflammatory and oncogenic diseases of the hepatobiliary tract as well as the gastrointestine [22] may encourage further strategies for treatment and prevention of the diseases to include use of inhibitors of metalloprotease enzymes [17]. Stimulation of MMP expression on enteric and biliary epithelial cells as well as hepatocytes may potentially be an important pathogenic effect of the Helicobacter species colonizing the hepatobiliary and the gastrointestinal tract. 


\section{Acknowledgements}

This study was supported by grants from the Royal Physiographic Society in Lund, the Swedish Medical Research Council (16×04723), University Hospital of Lund (ALF) and the Faculty of Medicine, University of Lund. 


\section{Figure legends}

Figure 1. Effect of gastric and enteric Helicobacter strains on MMP-2 expression. $\underline{\boldsymbol{H}}$. pullorum, H. pylori17874, H. pylori 15/96, $\underline{\text { H. cholecystus, } \boldsymbol{H} \text {. bilis and } \boldsymbol{H} \text {. hepaticus strains }}$ described in materials and methods were co-cultured with HT29, HepG2 or TFK-1. The expression level of MMP-2 was measured at 24 hours, and was compared to the uninfected cells. Optical density of wells incubated with secondary antibody only was subtracted from the sample data. Data presented are mean values (error bars, standard deviation) of nine samples from three separate experiments performed in triplicates. ${ }^{*} p<0.05,{ }^{*} p<0.01$, 苂* $9 \leq 0,001$, Mann-Whitney $U$ test.

Figure 2. Effect of gastric and enteric Helicobacter strains on MMP-9 expression. $\underline{\boldsymbol{H}}$. pullorum, $H$. pylori17874, H. pylori 15/96, $\underline{H}$. cholecystus, $\boldsymbol{H}$. bilis and $\boldsymbol{H}$. hepaticus strains described in materials and methods were co-cultured with HT29, HepG2 or TFK-1. The expression level of MMP-9 was measured at 24 hours, and was compared to the uninfected cells. Optical density of wells incubated with secondary antibody only was subtracted from the sample data. Data presented are mean values (error bars, standard deviation) of nine samples from three separate experiments performed in triplicates. ${ }^{*} p<0.05$, ${ }^{*} *_{p} \leq 0.01$, Mann-Whitney $U$ test. 
Figure 3. Effect of gastric and enteric Helicobacter strains on MMP-7 expression. $\underline{\boldsymbol{H}}$. pullorum, $H$. pylori17874, H. pylori 15/96, $\underline{H}$. cholecystus, $H$. bilis and $H$. hepaticus strains described in materials and methods were co-cultured with HT29. The expression level of MMP-7 was measured at 24 hours, and was compared to the uninfected cells. Optical density of wells incubated with secondary antibody only was subtracted from the sample data. Data presented are mean values (error bars, standard deviation) of nine samples from three separate experiments performed in triplicates. ${ }^{*} p<0.05$, Mann-Whitney $U$ test.

Figure 4. Immunohistochemistry of HT29 infected with gastric and enteric Helicobacter strains. HT29 cells were co-cultured with $\underline{\text { H. pullorum }}$ (B), H. pylori 17874 (C), H. pylori 15/96 (D), $\underline{H}$. cholecystus $(\mathrm{E}), \underline{H}$. bilis $(\mathrm{F})$ and $H$. hepaticus $(\mathrm{G})$ strains described in materials and methods for 24 hours, or left uninfected (A). Antibody against MMP-7 was visualized by DAB substrate, counter stained with hematoxylin. Original magnification $\times 10$.

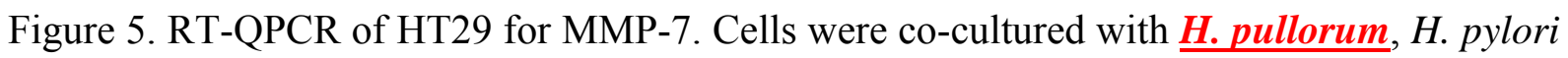
17874, H. pylori $15 / 96$ and $\underline{\boldsymbol{H}}$. cholecystus strains described in materials and methods for 24 hours, or left uninfected. Total RNA was reverse transcribed and cDNA was amplified in a Real-Time DNA thermal cycler. Threshold cycle $\left(\mathrm{C}_{\mathrm{T}}\right)$ was calculated on Rotorgene software (Corbett Research). Data are fold induction of $\mathrm{Ct}^{-1}$ values normalized against GAPDH mRNA in a corresponding sample. Data presented are mean values of triplicated samples in one representative experiment of three performed. 


\section{References}

[1] Fox, J.G. (2002) The non-H pylori helicobacters: their expanding role in gastrointestinal and systemic diseases. Gut. 50, 273-283.

[2] Stanley, J., Linton, D., Burnens, A.P., Dewhirst, F.E., On, S.L., Porter, A., Owen, R.J. and Costas, M. (1994) Helicobacter pullorum sp. nov.-genotype and phenotype of a new species isolated from poultry and from human patients with gastroenteritis. Microbiology. 140 (Pt 12), 3441-3449.

[3] Burnens, A.P., Stanley, J., Morgenstern, R. and Nicolet, J. (1994) Gastroenteritis associated with Helicobacter pullorum. Lancet. 344, 1569-1570.

[4] Fox, J.G., Yan, L.L., Dewhirst, F.E., Paster, B.J., Shames, B., Murphy, J.C., Hayward, A., Belcher, J.C. and Mendes, E.N. (1995) Helicobacter bilis sp. nov., a novel Helicobacter species isolated from bile, livers, and intestines of aged, inbred mice. J. Clin. Microbiol. 33, 445-454.

[5] Fox, J.G., Dewhirst, F.E., Tully, J.G., Paster, B.J., Yan, L., Taylor, N.S., Collins, M.J.,Jr., Gorelick, P.L. and Ward, J.M. (1994) Helicobacter hepaticus sp. nov., a microaerophilic bacterium isolated from livers and intestinal mucosal scrapings from mice. J. Clin. Microbiol. 32, 1238-1245.

[6] Franklin, C.L., Beckwith, C.S., Livingston, R.S., Riley, L.K., Gibson, S.V., BeschWilliford, C.L. and Hook, R.R.,Jr. (1996) Isolation of a novel Helicobacter species, Helicobacter cholecystus sp. nov., from the gallbladders of Syrian hamsters with cholangiofibrosis and centrilobular pancreatitis. J. Clin. Microbiol. 34, 2952-2958.

[7] Wotherspoon, A.C., Ortiz-Hidalgo, C., Falzon, M.R., Isaacson and P.G. (1991) Helicobacter pylori-associated gastritis and primary B-cell gastric lymphoma. Lancet. $338,1175-1176$. 
[8] Imper, V. and van Wart, H.E. Substrate specificity and mechanisms of substrate recognition of the matrix metalloprteases. California: Academic Press, 1998.

[9] Kleiner, D.E. and Stetler-Stevenson, W.G. (1999) Matrix metalloproteinases and metastasis. Cancer Chemother Pharmacol. 43 Suppl, S42-51.

[10] Mori, N., Sato, H., Hayashibara, T., Senba, M., Geleziunas, R., Wada, A., Hirayama, T. and Yamamoto, N. (2003) Helicobacter pylori induces matrix metalloproteinase-9 through activation of nuclear factor kappaB. Gastroenterology. 124, 983-992.

[11] Bebb, J.R., Letley, D.P., Thomas, R.J., Aviles, F., Collins, H.M., Watson, S.A., Hand, N.M., Zaitoun, A. and Atherton, J.C. (2003) Helicobacter pylori upregulates matrilysin (MMP-7) in epithelial cells in vivo and in vitro in a Cag dependent manner. Gut. 52, 1408-1413.

[12] Altschul, S.F., Madden, T.L., Schaffer, A.A., Zhang, J., Zhang, Z., Miller, W. and Lipman, D.J. (1997) Gapped BLAST and PSI-BLAST: a new generation of protein database search programs. Nucleic. Acids. Res. 25, 3389-3402.

[13] Keates, S., Keates, A.C., Warny, M., Peek, R.M.,Jr., Murray, P.G. and Kelly, C.P. (1999) Differential activation of mitogen-activated protein kinases in AGS gastric epithelial cells by cag+ and cag- Helicobacter pylori. J. Immunol. 163, 5552-9.

[14] Okada, N., Ishida, H., Murata, N., Hashimoto, D., Seyama, Y. and Kubota, S. (2001) Matrix metalloproteinase-2 and -9 in bile as a marker of liver metastasis in colorectal cancer. Biochem. Biophys. Res. Commun. 19, 212-216.

[15] Jo Chae, K., Rha, S.Y., Oh, B.K., Koo, J.S., Kim, Y.J., Choi, J., Park, C. and Park, Y.N. (2004) Expression of matrix metalloproteinase-2 and -9 and tissue inhibitor of metalloproteinase-1 and -2 in intraductal and nonintraductal growth type of cholangiocarcinoma. Am. J. Gastroenterol. 99, 68-75. 
[16] Wilson, C.L., Heppner, K.J., Labosky, P.A., Hogan, B.L. and Matrisian, L.M. (1997) Intestinal tumorigenesis is suppressed in mice lacking the metalloproteinase matrilysin. Proc. Natl. Acad. Sci. U S A. 18, 1402-7.

[17] Wielockx, B., Libert, C. and Wilson, C. (2004) Matrilysin (matrix metalloproteinase7): a new promising drug target in cancer and inflammation? Cytokine \& Growth Factor Rev. 15, 111-115.

[18] Lopez-Boado, Y.S., Wilson, C.L. and Parks, W.C. (2001) Regulation of matrilysin expression in airway epithelial cells by Pseudomonas aeruginosa flaggelin. J. Biol. Chem. 276, 41417-41423.

[19] Crawford, H.C., Krishna, U.S., Israel, D.A., Matrisian, L.M., Washington, M.K. and Peek, R.M.,Jr. (2003) Helicobacter pylori strain-selective induction of matrix metalloproteinase-7 in vitro and within gastric mucosa. Gastroenterology. 125, 11251136.

[20] Wroblewski, L.E., Noble, P.J., Pagliocca, A., Pritchard, D.M., Hart, C.A., Campbell, F., Dodson, A.R., Dockray, G.J. and Varro, A. (2003) Stimulation of MMP-7 (matrilysin) by Helicobacter pylori in human gastric epithelial cells: role in epithelial cell migration. J. Cell. Sci. 15, 3017-3026.

[21] Chien, C.C., Taylor, N.S., Ge, Z., Schauer, D.B., Young, V.B. and Fox, J.G. (2000) Identification of $c d t B$ homologues and cytolethal distending toxin activity in enterohepatic Helicobacter spp. J. Med. Microbiol. 49, 525-534.

[22] Baugh, M.D., Perry, M.J., Hollander, A.P., Davies, D.R., Cross, S.S., Lobo, A.J., Taylor, C.J. and Evans, G.S. (1999) Matrix metalloproteinase levels are elevated in inflammatory bowel disease. Gastroenterol. Int. 117, 814-822. 
Figure 1

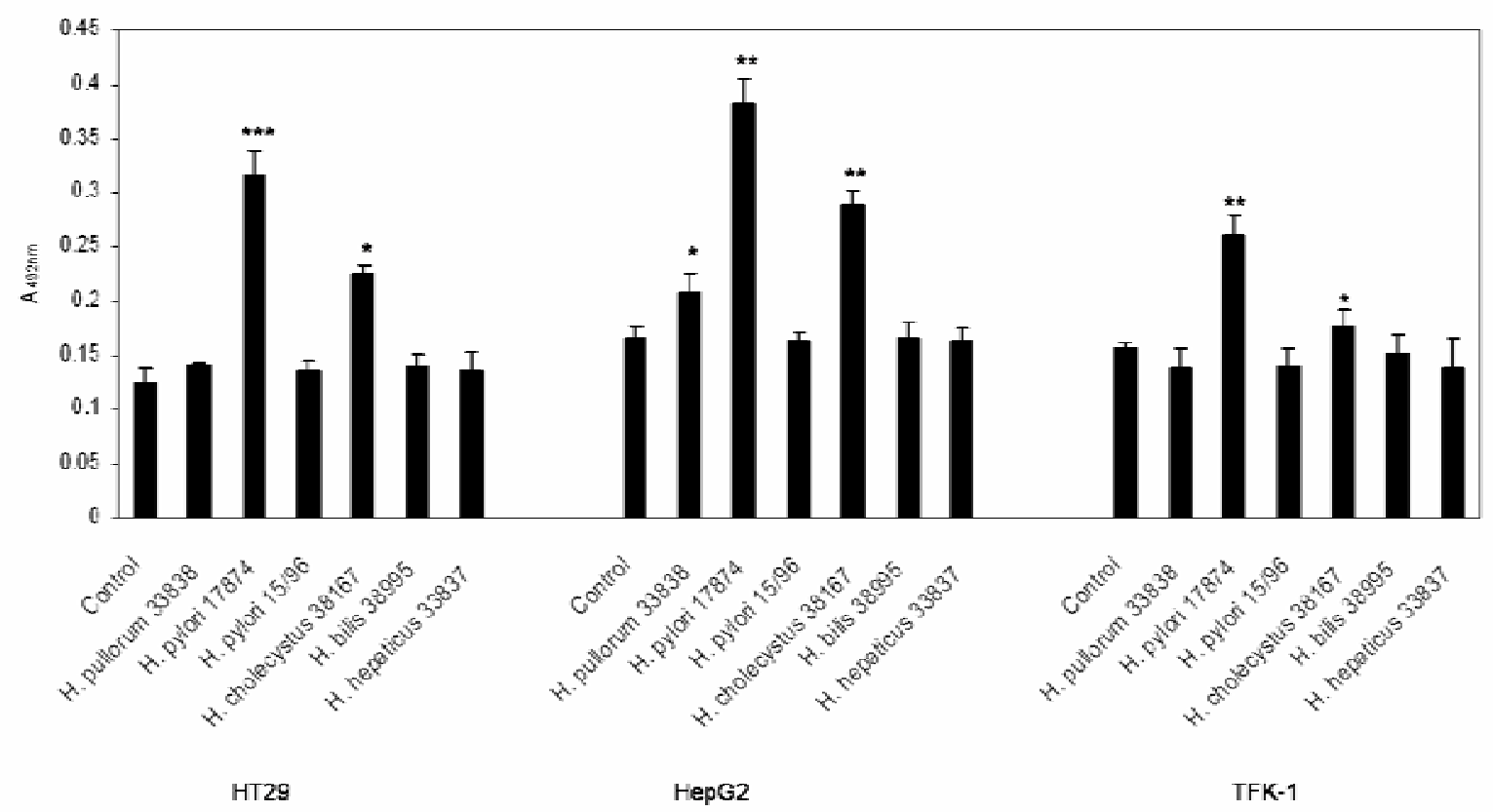


Figure 2

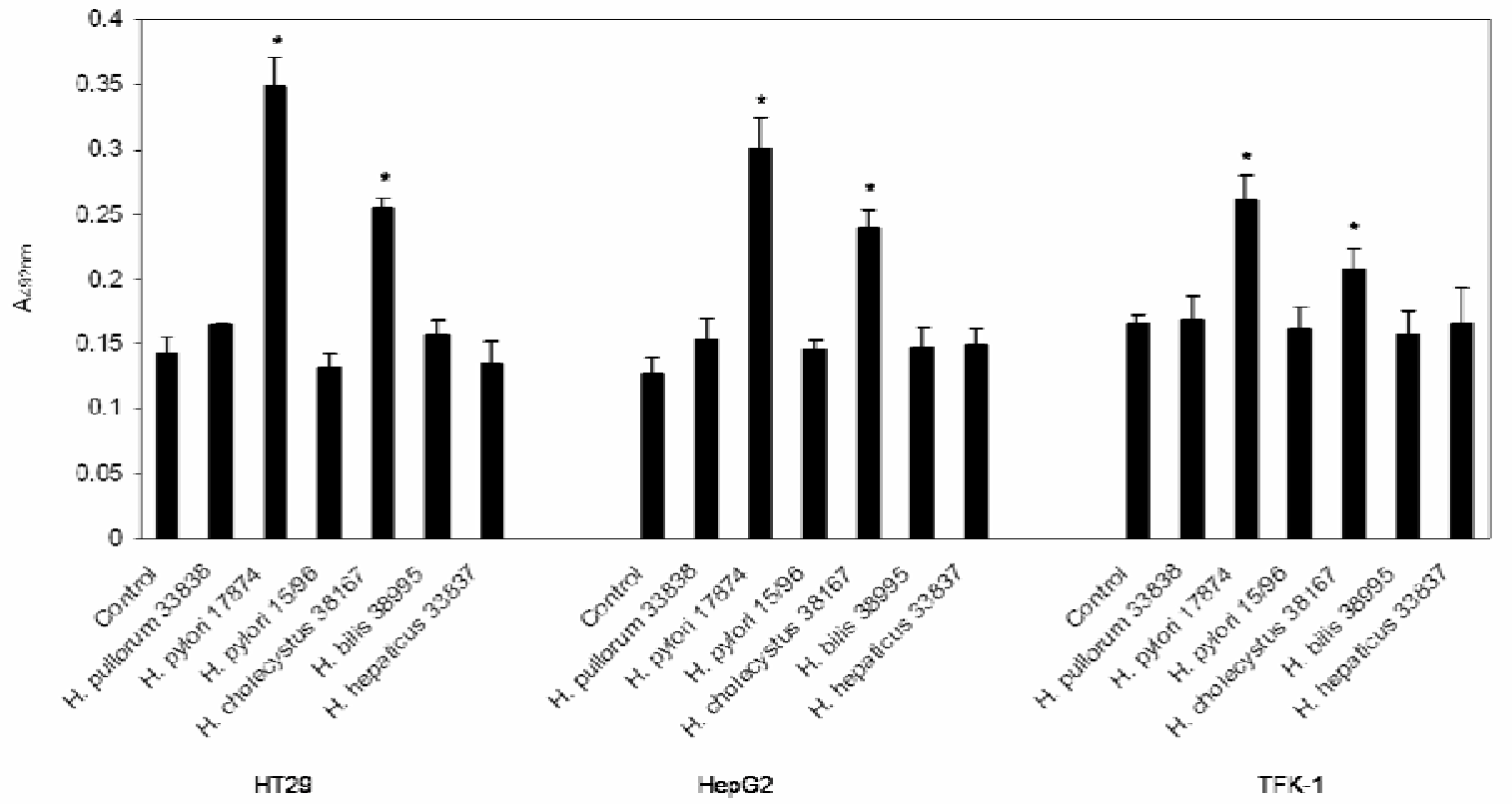


Figure 3

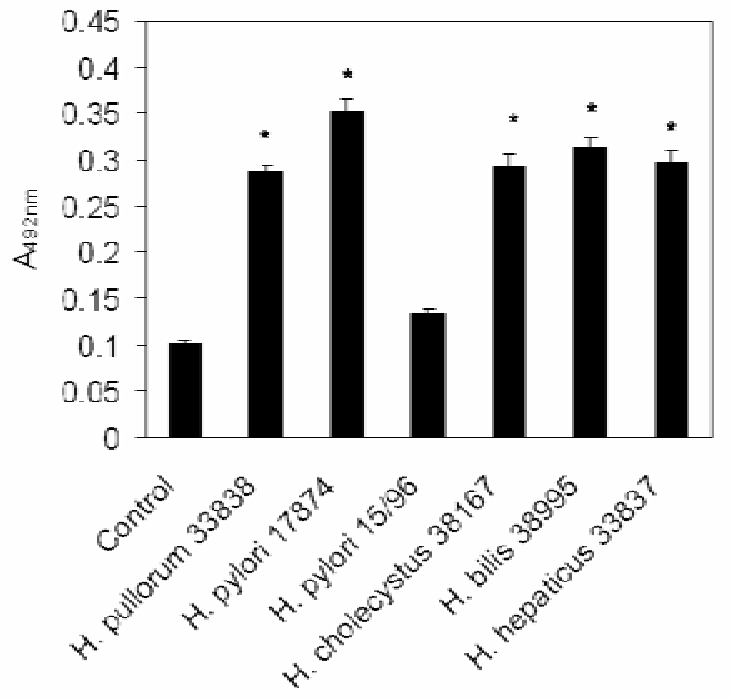


Figure 4
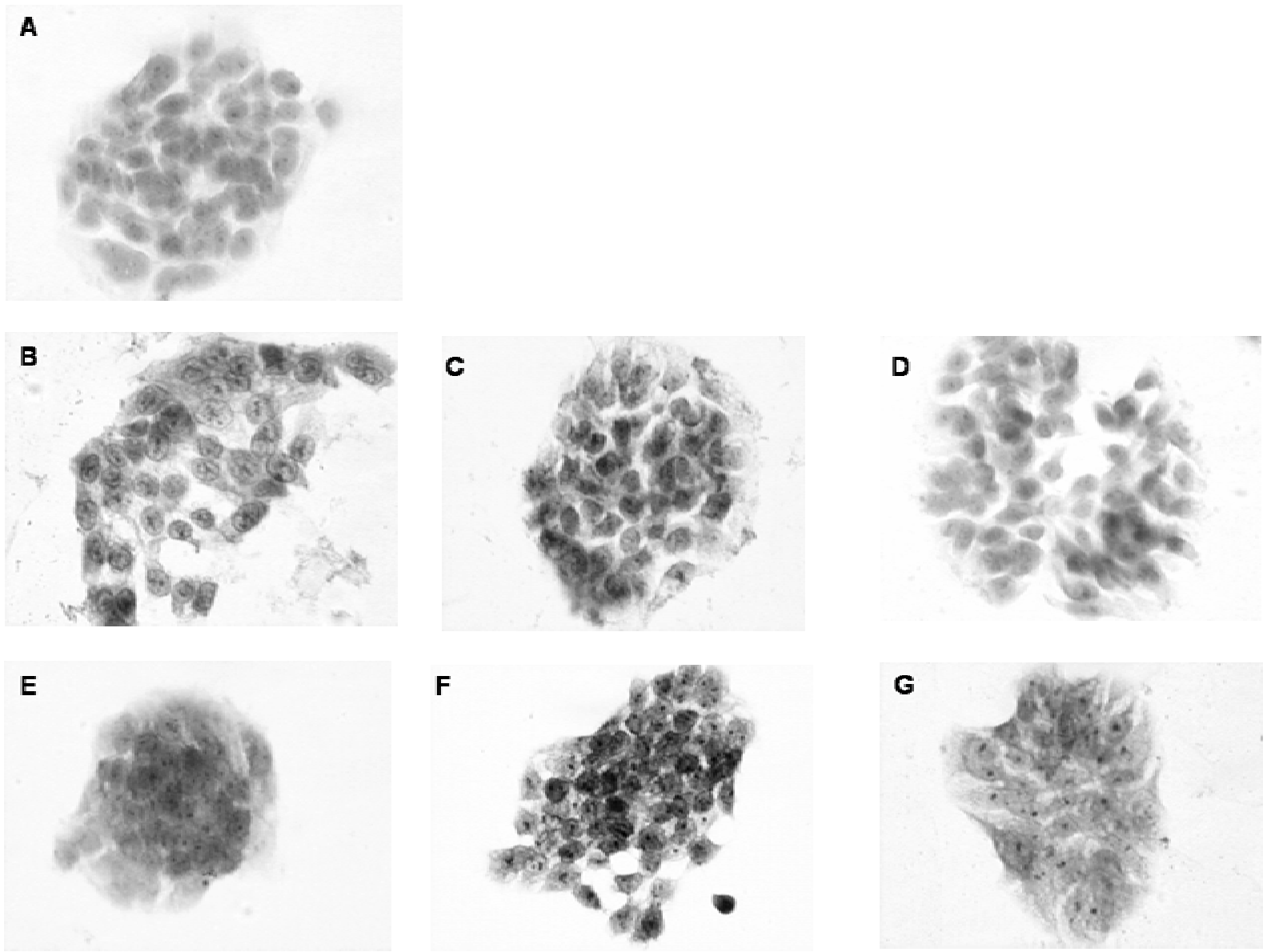
Figure 5

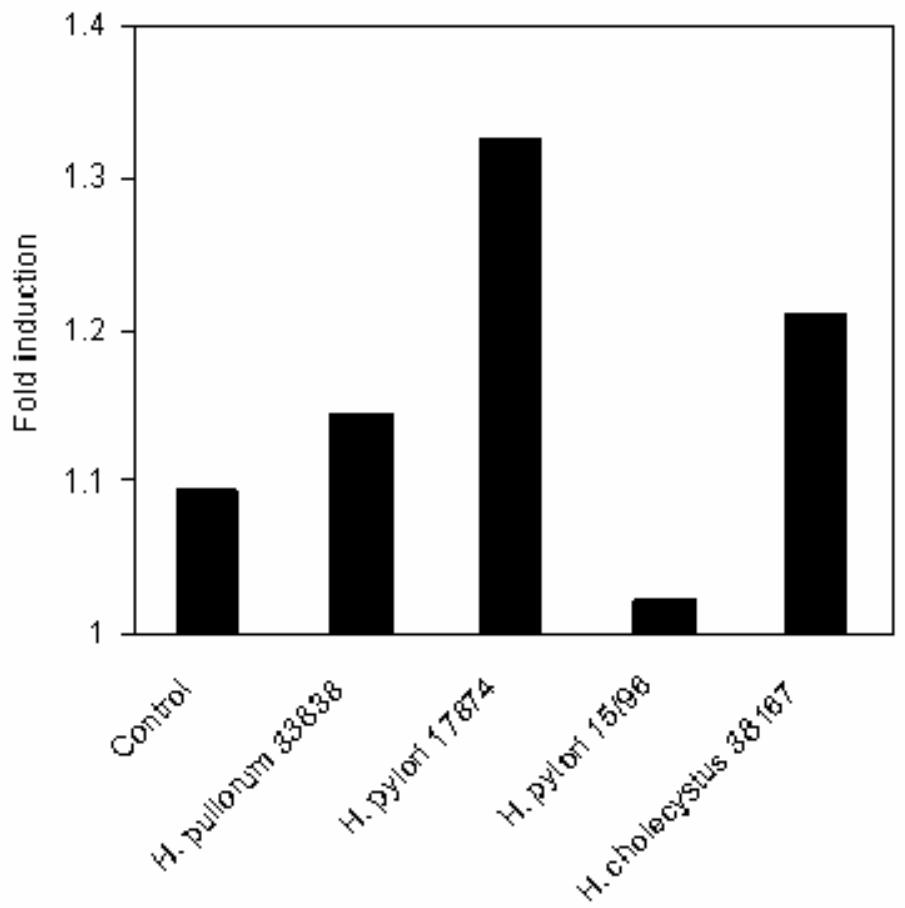

